\title{
A qualitative exploration of the experiences of adolescents with alopecia areata and their messages for healthcare professionals
}

Dear Editor,

Alopecia areata (AA) is an autoimmune disorder characterised by non-scarring hair loss, which affects nearly $2 \%$ of the population with $60 \%$ experiencing their first episode of hair loss before the age of $20^{12}$. The pattern of hair loss is highly variable and unpredictable, from well-defined patches to total hair loss. AA can have a transformative effect on an individual, and has significant psychological consequences for many, with high levels of anxiety and depression well-documented ${ }^{34}$. These effects can be particularly profound in adolescence ${ }^{5}$, with $A A$ an additional challenge affecting appearance during a critical period for self-image.

We conducted a secondary inductive thematic analysis of 21 in-depth semi-structured interviews with young people with $\mathrm{AA}^{6}$. 18 participants were female, 3 male; the mean age was 21.5 years (range 14-23 years old); the mean length of time since diagnosis was 8.4 years. 17 participants identified as White British, and 1 participant identified as each of the following: Asian/White, Black Caribbean, European and Indian. Our analysis identified the following core emotional/psychological themes: i) Isolation and community: most participants made reference to 'alopecia as a hidden problem', and 'felt very alone' when diagnosed. However, many found tremendous support in online forums/support groups in which they could share experiences with other people with AA. ii) Self-consciousness: participants cited feeling 'paranoid' about being stared at, sometimes to the extent that they could not leave the house. iii) 'It's not just hair': the concept of AA being far more than hair loss was prominent throughout; some felt they lost 'their identity' and some young women felt it had impacted their 'femininity'. Societal connotations of hair loss also frequently posed a challenge, with many people presuming young people with AA had cancer. iv) Unpredictability: some participants described 'not knowing' whether their hair would grow back as the most difficult part of their experience, and were 'living in fear' that their hair would fall out again even after experiencing re-growth. One individual described how having alopecia felt like 'you're harnessed into that rollercoaster and no matter what, it will just go up and down and stop and start whenever'. Some individuals recounted shaving off their hair as a way of taking back control in their tumultuous disease course.

Importantly, there was a notable heterogeneity amongst participant responses; although the majority felt that their alopecia had been tremendously difficult, others felt that it had made them a better and/or more unique person. A conflict in perspectives was sometimes observed within individual participant accounts, likely reflecting both the ongoing 'alopecia journey' and adolescence as a time of major change.

An awareness of these complex psychological themes is crucial to the provision of high-quality, developmentally appropriate care for adolescents with AA. Via analysis of the whole transcripts, we identified two overarching messages for healthcare professionals managing adolescents with AA: a) Give more information and b) Address the emotional impact (see Figure 1 for illustrative data extracts). These themes intersect; the failure to address a patient's information needs reflected a lack of understanding of emotional impact in certain cases. Some individuals described how this could impact on treatment options. One participant recounted that 'they didn't give me any information on wigs or anything which was quite tough, because we didn't realise that I was entitled to free wigs.' Although the British Association of Dermatologists guidelines for management of AA recommends considering psychological support ${ }^{7}$, our participants frequently cited a failure of their general practitioner or dermatologist to do so, with 'so much focus on scientific side...[they] don't really understand the social impact'. This is echoed in existing literature; in a questionnaire-based study investigating effect of alopecia on quality of life, $40 \%$ of respondents reported feeling that their doctors had been either 'insensitive', dismissive' or 'unsupportive' ${ }^{8}$.

There are likely several reasons for the failure of many healthcare professionals to address the emotional impact of $A A$, including consultation time-constraints, but it is essential. For many young people, alopecia is 
their first experience of a condition for which a cure cannot be offered. The experience of navigating health services and adjustment to a chronic condition may be overwhelming, while also dealing with the conspicuous nature of alopecia during a critical time in development of self. We suggest that increased awareness of the emotional issues patients might be experiencing combined with an appreciation of the valuable role of appropriate online support and information, will better equip healthcare professionals.

Our analysis provides insight into the complexity and challenges of the experiences of young people living with $\mathrm{AA}$, and provides patient-voices in informing healthcare delivery. We have distilled two simple but crucial messages for professionals managing adolescents with $A A$.

ACKNOWLEDGEMENTS: we would like to thank the Medical Sociology \& Health Experiences Research Group (University of Oxford) for data sharing and to the young people who took part in the original data collection project.

AUTHORS: I de Vere Hunt ${ }^{1}$, A McNiven ${ }^{2}$, T McPherson ${ }^{3}$

${ }^{1}$ Medical Sciences Division, John Radcliffe Hospital, Oxford, OX3 9DU, U.K.; ${ }^{2}$ Nuffield Department of Primary Care Health Sciences, Radcliffe Observatory Quarter, Woodstock Road, Oxford, OX2 6GG, U.K. and ${ }^{3}$ Department of Dermatology, Churchill Hospital, Oxford University Hospitals Trust, Oxford, OX3 7LE, U.K

Correspondence: Tess McPherson

Email: tess.mcpherson@ouh.nhs.uk

\section{REFERENCES}

1. Pratt CH, King LE, Messenger AG, Christiano AM, Sundberg JP. Alopecia areata. Nat Rev Dis Primer. 2017 Mar 16;3(1):1-17.

2. MacLean KJ, Tidman MJ. Alopecia areata: more than skin deep. The Practitioner. 2013 Sep;257(1764):29-32, 3.

3. Hunt N, McHale S. The psychological impact of alopecia. BMJ. 2005 Oct 20;331(7522):951-3.

4. Aldhouse NVJ, Kitchen H, Knight S, Macey J, Nunes FP, Dutronc Y, et al. "'You lose your hair, what's the big deal?" I was so embarrassed, I was so self-conscious, I was so depressed:' a qualitative interview study to understand the psychosocial burden of alopecia areata. J Patient-Rep Outcomes. 2020 Sep 11;4(1):76.

5. Bilgiç Ö, Bilgiç A, Bahalı K, Bahali A g., Gürkan A, Yılmaz S. Psychiatric symptomatology and health-related quality of life in children and adolescents with alopecia areata. J Eur Acad Dermatol Venereol. 2014 Nov 1;28(11):1463-8.

6. Healthtalk [Internet]. [cited 2020 Mar 18]. Available from: https://healthtalk.org/

7. Messenger A g., McKillop J, Farrant P, McDonagh A j., Sladden M. British Association of Dermatologists' guidelines for the management of alopecia areata 2012. Br J Dermatol. 2012 May 1;166(5):916-26.

8. Williamson D, Gonzalez M, Finlay A. The effect of hair loss on quality of life. J Eur Acad Dermatol Venereol. 2001 Mar 1;15(2):137-9. 
FUNDING: this study was supported by Oxfordshire Health Services Research Committee (OHSRC) part of Oxford Hospitals Charity. Data collection was funded by National Institute for Health Research under the Research for Patient Benefit programme (PB-PG-0213-30006).

ETHICS: ethical approval was obtained by Berkshire NRES Committee South Central. All participants gave informed consent before taking part and consent for secondary analysis. The University of Oxford, which holds the copyright for the interviews, has given data sharing permission to enable this secondary analysis of the interview data.

\section{CONFLICTS OF INTEREST: none to declare}

Figure 1: Illustrative data extracts for key 'messages to healthcare professionals' themes

\begin{tabular}{|c|c|}
\hline Key theme & Illustrative data extract \\
\hline \multirow[t]{5}{*}{$\begin{array}{l}\text { Give more } \\
\text { information }\end{array}$} & $\begin{array}{l}\text { "They don't tell you that much. Like only like two years ago I found out the actual name of the } \\
\text { alopecia areata I have which I can't pronounce because no one's said it to me." (4) }\end{array}$ \\
\hline & $\begin{array}{l}\text { "I think most of the explanation was, "Look on Alopecia UK, they have a section about what } \\
\text { alopecia is. Get your information from there... } \\
\text { Am I ill then? Am I sick? Am I okay? Do I have a disease? Like what's going on?" (1) }\end{array}$ \\
\hline & $\begin{array}{l}\text { "I did initially ask the dermatologist and doctor and stuff and they sort of said, 'Look on the } \\
\text { internet, sort of yellowpages'. So, they kind of left me out on my own." (9) }\end{array}$ \\
\hline & $\begin{array}{l}\text { "'Have you Googled alopecia?' and I said 'Yeah,' he said 'Well that will tell you all you need to } \\
\text { know.' That's just what he said to me... if he'd have maybe just spent an extra five minutes with } \\
\text { me explaining why." (19) }\end{array}$ \\
\hline & $\begin{array}{l}\text { "They didn't give me any information on wigs or anything which was quite tough, because we } \\
\text { didn't realise that I was entitled to free wigs. And so, for, for the first, I think it was first three } \\
\text { years, two or three years - I was buying my own wigs." (10) }\end{array}$ \\
\hline \multirow[t]{5}{*}{$\begin{array}{l}\text { Address the } \\
\text { emotional } \\
\text { impact }\end{array}$} & $\begin{array}{l}\text { "I'd say doctors in general need to be aware of the psychological impacts of alopecia, and the } \\
\text { struggles that young people go through anyway. it's not just a physical thing. Like you need to } \\
\text { acknowledge that they may be struggling." (18) }\end{array}$ \\
\hline & $\begin{array}{l}\text { "I think they just because they're very medical kind of people they kinda see everything black and } \\
\text { white." (15) }\end{array}$ \\
\hline & $\begin{array}{l}\text { “Doctors-wise, like I said, it would be nice to have someone just be like, 'How's your hair doing?' } \\
\text { 'How are you feeling about it?' And just talk about it." (16) }\end{array}$ \\
\hline & $\begin{array}{l}\text { "Sometimes it is just such a quick thing of 'you have alopecia, this is what it is, we've not found an } \\
\text { answer' and it's just like 'goodbye' - so it's just like bish, bash, bosh. And for someone that's losing } \\
\text { their hair, it's not as quick as telling them what it is and saying goodbye." (10) }\end{array}$ \\
\hline & "Think about them as a person - not as someone who has a bald patch there." (20) \\
\hline
\end{tabular}

